\title{
A Precarização do Emprego na Europa
}

\author{
Luísa Oliveira \\ Helena Carvalho
}

\begin{abstract}
precariedade do emprego é um dos indicadores mais relevantes
A para analisarmos as transformações estruturais que têm ocorrido nos mercados de trabalho europeus nas duas últimas décadas. Alguns autores falam já do assalariado da precariedade (Paugam, 2000) ou da impossiblidade do emprego seguro (Auer e Gazier, 2006), modalidade que marcou as relações de emprego no pós-guerra. A lógica de precarização do emprego opera uma dualização nos mercados de trabalho ao criar dois grupos de trabalhadores com condições de emprego e, portanto, também de trabalho bastante distintas. É de admitir que essa situação atinja sobretudo os mais jovens.
\end{abstract}

Um dos objetivos deste artigo é compreender em que medida essas hipóteses se verificam realmente, analisando a evolução de precarização do emprego em um conjunto de países da União Européia - UE nos últimos vinte anos. Pretende-se mapear os países em virtude de suas semelhanças e diferenças e ainda compreender se se trata de um fenômeno conjuntural ou se, pelo contrário, se está perante uma situação estrutural.

Um segundo objetivo visa compreender em que medida se verificam, de fato, clivagens geracionais no âmbito de precarização do emprego. Analisam-se ainda as diferenças entre países no que diz respeito à extensão do fenômeno de precarização e seu impacto em três gerações

DADOS - Revista de Ciências Sociais, Rio de Janeiro, Vol. 51, n3, 2008, pp. 541 a 567. 
distintas. Nessa abordagem geracional, foram definidos perfis-tipo dos países segundo as razões alegadas pelos indivíduos para terem trabalho temporário. O estudo foi feito com base em informação estatística do Gabinete de Estatísticas da União Européia - Eurostat, e a análise articulou a comparação intra e interpaíses aplicando-se a Principal Components Analysis for Categorical Data - CatPca para a definição dos perfis-tipo.

\section{TRANSFORMAÇÃO DAS RELAÇÕES DE EMPREGO}

Nos últimos vinte anos, ocorreram transformações profundas nos mercados de trabalho europeus, com impactos significativos não apenas nas condições de trabalho e de emprego dos indivíduos, mas também em seus modos de vida. Com efeito, a precariedade do emprego não se restringe ao impacto econômico na vida dos indivíduos e das famílias, gerando também sentimentos de insegurança e de medo, um retraimento diante da possibilidade de construir projetos de vida e de organizar o futuro. Isso já levou alguns autores a associar a noção de risco, em face das incertezas do mercado, aos riscos da modernidade de que nos fala Beck (1992), na medida em que ela age como "um princípio de desmoralização, de dissociação social [...] que impregna a vida quotidiana, dissolve os laços sociais e mina as estruturas psíquicas dos indivíduos" (Castel, 2003:29), em uma espécie de corrosão do carácter, para usarmos a expressão de Sennett (2001). Este problema pode estar no centro de uma desagregação social e explicar alguns fenômenos anômicos que caracterizam a modernidade.

Essa noção alargada de precariedade ${ }^{1}$ não se restringe às relações de emprego, abarcando também suas conseqüências objetivas e subjetivas na vida dos indivíduos e dos grupos. Neste artigo, utilizamos uma concepção mais restrita: emprego precário, entendido como um conjunto de formas atípicas de emprego ${ }^{2}$ no quadro das condições sociojurídicas das relações de emprego. Isso significa que se excluiu da análise o fenômeno da precariedade entendido como sinônimo de desqualificação social ou de condições de vida reportadas à pobreza ou à exclusão social, no sentido de Le Blanc (2007) quando se refere, por exemplo, a vidas precárias. Nosso objeto neste texto se concentra nas relações de emprego. Partimos assim do pressuposto de que a precariedade do emprego é majoritariamente uma situação a que os indivíduos são compelidos, e não uma opção própria ${ }^{3}$. 
A comparação entre a crise econômica que assolou o mundo ocidental nos anos 1930 e a que vivemos desde os anos 1970, a partir da noção de relação salarial ${ }^{4}$ (Boyer, 1981), continua sendo uma das perspectivas mais pertinentes e elucidativas sobre as transformações estruturais dos mercados de trabalho. O traço mais marcante da passagem de uma lógica concorrencial a uma lógica fordista, no que diz respeito ao mercado de trabalho, foi o fato de a relação de trabalho ter deixado de ser uma relação puramente mercantil. Passando a ser regulada juridicamente, deu lugar à noção de emprego, mudando radicalmente as condições de trabalho e de vida dos indivíduos. A garantia de emprego - o contrato por tempo indeterminado - e a proteção social estão mesmo na origem da chamada cidadania social na Europa ocidental do pósguerra. A proteção social inaugura os direitos no trabalho e faz desaparecer a lógica caritativa da esmola aos desprotegidos (Castel, 1995).

Nesse quadro, o Estado-Providência funcionou não só como um regulador ativo, mas também como um ator fundamental na construção social dos mercados de trabalho - por meio da implementação e da gestão de políticas sociais - e um promotor de cidadania. A crise do Estado-Providência, desencadeada por um conjunto de fatores que não serão discutidos aqui, pôs em causa esse modelo. A hipótese do retorno a uma relação salarial de tipo concorrencial, nos termos em que era definida no início do século passado, não faz sentido, dado que, comparativamente, são mantidos níveis de proteção social que então não existiam. Cabe sublinhar que há diferenças marcantes entre os países da UE no que diz respeito a esses níveis de proteção (Ferrera, Hemerijck e Rhodes, 2000). Os países nórdicos têm um modelo socialdemocrata; Áustria, França, Alemanha e Itália aproximam-se mais de um modelo corporativista; os países do sul da Europa constituem um grupo em que os Estados-Providência não foram tão longe em suas medidas de proteção social (Esping-Andersen, 1990); os países do leste europeu, por algumas razões históricas bem conhecidas, constituem ainda outro grupo.

Nesse quadro, a reconstrução e a reconfiguração social dos mercados de trabalho vêm ocorrendo há três décadas em meio a controvérsias sociais, políticas e mesmo científicas entre os diferentes atores sociais envolvidos. As reivindicações e a pressão política dos empregadores para a liberalização dos mercados de trabalho - juntamente com as estratégias de reorganização das empresas - têm encontrado eco no âmbito político, o que se traduziu, na ordem jurídica, pela invenção dos 
contratos a termo certo e outras formas atípicas de emprego (Kovács, 2005), além de uma maior facilidade em demitir em certos países. O argumento de aspecto mais liberal - associado ao apelo da limitação das funções do Estado - é que a rigidez dos mercados de trabalho impede o aumento da competitividade das empresas e dos países. O contra-argumento, de feição mais socialdemocrata, aceitando o princípio de liberalização dos mercados, põe a tônica na necessidade de manter o Modelo Social Europeu para promover a inclusão social. Uma maior criação de riqueza - um período de expansão econômica idêntico ao que marcou as economias européias no pós-guerra - permitiria resolver os problemas financeiros do Estado, além de uma melhor distribuição da riqueza, viabilizando políticas e medidas de proteção social mais justas. Essa é a perspectiva que sustenta a chamada Agenda de Lisboa quando põe lado a lado o desafio de aumentar a competitividade e a inclusão social (Rodrigues, 2000).

Tal controvérsia - nem sempre explicitamente assumida - pôs, no início dos anos 1980, a problemática da flexibilidade do mercado de trabalho no centro da discussão acadêmica (Boyer, 1986). No entanto, a flexibilidade é uma noção polissêmica, ou seja, cobre um leque vasto de situações: flexibilidade no trabalho (polivalência); flexibilidade nas condições de emprego (horários, distribuição da duração do trabalho ao longo da vida etc.); e liberalização da relação de emprego (liberdade para demitir). Em uma tentativa de definir melhor os contornos do debate, propôs-se, no campo acadêmico, a diferenciação entre flexibilidade defensiva e flexibilidade ofensiva (Rodrigues, 1988), mas a controvérsia só viria a clarificar-se com a introdução recente da noção de flexigurança e o caso da Dinamarca como exemplo de referência. O que marca distintamente o caso dinamarquês, do ponto de vista mais estrutural (Madsen, 2004), é uma longa tradição de liberalização das demissões que data do final do século XIX-, situação que é compensada, digamos assim, por um Estado-Providência forte. Isso permite medidas de proteção social que não se limitam a políticas ativas de emprego e de formação, mas abrangem o ciclo de vida dos indivíduos e asseguram condições de vida digna em períodos de maior carência; por exemplo, situações de desemprego, doença e velhice.

Hoje, a questão central na maioria dos países europeus é dar ou não o passo para a liberalização das demissões, tendo como contrapartida a manutenção ou o reforço dos mecanismos de segurança social. Esse ideal-tipo de organização dos mercados de trabalho permitiria a ma- 
nutenção de níveis de vida decentes, para utilizarmos a designação da Organização Internacional do Trabalho - OIT, a defesa da cidadania social e um aumento da esperança de reencontrar novo emprego, através da formação ao longo da vida, independentemente do tipo de contrato e até da situação perante o emprego. Contudo, essa solução pressupõe uma dinamização da atividade econômica e do crescimento, passível de sustentar taxas elevadas de emprego e, portanto, de sustentação do modelo social.

$\mathrm{O}$ argumento sobre a rigidez dos mercados de trabalho como fator inibidor do aumento de competitividade das empresas e dos países encerra, em uma primeira leitura, um mistério: se é possível, pela regulação jurídica dos contratos a termo certo, uma tão grande flexibilidade em recrutar e exteriorizar mão-de-obra de acordo com as necessidades conjunturais das empresas, por que é que se fala em rigidez do mercado de trabalho? A pergunta parece naïve, porque também se sabe que o mecanismo jurídico dos contratos a termo certo criou uma dualização no grupo dos trabalhadores: de um lado os que têm contrato por tempo indeterminado - a que alguns autores se referem como núcleo duro -, com carreiras profissionais asseguradas e os direitos que esse tipo de relação salarial confere; de outro, os assalariados da precariedade, para utilizarmos a expressão de Paugam (2000), de futuro profissional incerto.

Quando se fala em rigidez dos mercados de trabalho, fala-se sobretudo naquele "núcleo duro" de trabalhadores, digamos assim, que mantêm contratos por tempo indeterminado. É justamente por isso que se criou a idéia de que a precarização do emprego é um problema geracional, estando os mais jovens sempre em desvantagem.

A questão é complexa e encerra vários paradoxos. O primeiro é que, liberalizando juridicamente as demissões, esse núcleo duro, por questões de idade e de nível de escolarização, será o que terá mais dificuldades em encontrar um novo emprego. Mesmo o caso dinamarquês parece não estar imune a essa situação, embora as taxas de desemprego tenham decrescido drasticamente e a Dinamarca se apresente como um dos países da UE em que essa taxa é ainda mais baixa ${ }^{5}$. Isso porque, como refere Madsen (2002), um dos problemas do modelo dinamarquês é o aumento de pessoas que estão sendo excluídas do mercado. Essa questão constitui aquilo a que chamamos de segundo paradoxo, no sentido em que a liberalização jurídica das demissões, tendo como 
alvo o núcleo duro - e, portanto, os trabalhadores mais idosos -, é contraditória com as políticas de envelhecimento ativo (OCDE, 2005; 2006) que a UE propõe $e^{6}$ e que visam manter as populações idosas mais tempo na ativa, o que permitiria, em princípio, aliviar as dificuldades financeiras da segurança social. O terceiro paradoxo é que as tensões sobre o mercado de trabalho por parte dos mais jovens tenderão a aumentar em um quadro de crise econômica que, naturalmente, é mais acentuada em certos países da UE e reforça as situações de desigualdade e de injustiça relativa (Dubet, 2006) entre cidadãos europeus e entre gerações, se tal hipótese se confirmar. Ademais, as gerações mais jovens são também as que têm níveis mais elevados de escolarização, o que leva à interrogação sobre o retorno do investimento no chamado capital humano nos âmbitos individual e coletivo e os efeitos de uma tal situação no desenvolvimento, dando por adquirida a tese do efeito positivo da educação no crescimento das economias (Aghion e Cohen, 2004).

Neste artigo, procuramos analisar alguns aspectos que contribuam para esclarecer esses paradoxos:

1. Podemos falar em generalização do emprego precário em todos os países da UE?

2. Trata-se de um fenômeno de natureza conjuntural ou, pelo contrário, estamos perante um traço que induz a uma reconfiguração estrutural dos mercados de trabalho?

3. Essa reconfiguração marca, de fato, uma dualização dos mercados entre gerações ou é um fenômeno que se alastra por todas as faixas de idade?

\section{METODOLOGIA}

Para responder a essas questões, trabalhamos a informação estatística relativa ao trabalho temporário a partir dos dados do Eurostat: Labour Force Survey - LFS'.

O Eurostat define trabalho temporário como um trabalho de duração determinada ou temporária (correntemente designado como trabalho a termo certo ou a prazo), se for acordado entre empregador e assalariado que o fim do emprego é determinado por condições objetivas, tais como a definição de uma data precisa para seu termo, a finalização de uma tarefa ou o retorno de outro assalariado que havia sido substituído temporariamente. 
Segundo essa definição, o trabalho temporário é um indicador potente de precarização do emprego, embora subavalie o fenômeno, uma vez que não cobre todas as situações de emprego precário, nomeadamente os fenômenos de trabalho em tempo parcial involuntário ${ }^{8}$, todas as formas de emprego clandestino ${ }^{9}$ e ainda os falsos trabalhadores independentes ${ }^{10}$. Sobre o trabalho temporário, tal como definido anteriormente, é possível contabilizar as situações voluntárias - isto é, as situações em que é opção dos indivíduos - e que não se enquadram, portanto, na lógica de precarização do emprego.

Os dados objeto de análise são os seguintes:

1. Taxa de trabalho temporário na Europa dos 25, para os indivíduos em idade ativa (15-64 anos) em 2005;

2. Taxa de trabalho temporário na Europa dos 15, para os indivíduos em idade ativa (15-64 anos) em três décadas: 1985, 1995 e 2005;

3. Taxa de trabalho temporário na Europa dos 15 em três faixas etárias: 15-24, 25-49 e 50-64 anos, em 2005;

4. Taxa de incidência em cada uma das principais razões para ter trabalho temporário, em função da idade (faixas indicadas acima), na Europa dos 15 em 2005;

5. Taxa de desemprego na Europa dos 15 em 2005.

Para responder às questões de investigação referidas, foram desenvolvidas duas estratégias analíticas. Começou por se realizar uma análise estrutural baseada nas taxas de trabalho temporário e de desemprego. A análise articulou a comparação intra e interpaíses. A fim de aferir se estamos perante um fenômeno transversal às diversas gerações ou se, pelo contrário, há um efeito geracional que atinge sobretudo os mais jovens, analisou-se a evolução das taxas de trabalho temporário por grupos de idade entre 1985 e 2005.

Procedeu-se ainda à identificação de perfis de países da Europa dos 15 no que respeita às razões alegadas para ter trabalho temporário. A saber, e segundo a fonte utilizada, essas razões são: não conseguir emprego permanente; não querer emprego permanente; estar em educação/formação; estar em estágio. Para o efeito, realizou-se uma análise multivariada usando a CatPca. Trata-se de uma análise de componentes principais não-linear, que permite articular variáveis quantitativas - taxas associadas a cada uma das quatro razões mencionadas para justificar a situação de trabalho temporário - com variáveis qualitativas, como é o 
caso da variável país (Geer, 1993a; 1993b; Gifi, 1996; Meulman, Kooij e Heiser, 2004). Com a aplicação da CatPca, foram identificados perfis-tipo que distinguem entre si grupos de países, evidenciando a existência de lógicas diferentes entre os países no que se refere à difusão do trabalho temporário em cada uma das gerações.

\section{EXTENSÃO DO TRABALHO TEMPORÁRIO NA UE}

Em termos gerais, verifica-se que o peso relativo do trabalho temporário no total da população empregada é bastante diferenciado segundo os países (Gráfico 1).

Os países do leste são os que, grosso modo, apresentam as taxas mais baixas, com exceção da Polônia - que ocupa o segundo lugar entre os países que apresentam uma maior penetração de trabalho temporário $(25,6 \%)$ - e da Eslovênia (17,2\%). Esses dados permitem concluir que o leste europeu apresenta situações diferenciadas e que alguns países seguem uma lógica mais concorrencial do que outros.

No entanto, essa conclusão deve ser relativizada, dado que a entrada desses países na UE se fez defasadamente no tempo, e esse aspecto é de relevância capital para a análise desse fenômeno.

A Espanha apresenta a taxa mais elevada de trabalho temporário $(33,4 \%)$. Portugal está em terceiro lugar, com 19,5\%. A posição de Portugal não deixa de ser surpreendente em face da idéia generalizada - a

\section{Gráfico 1}

Taxa de Trabalho Temporário em 2005 (EU a 25) por País

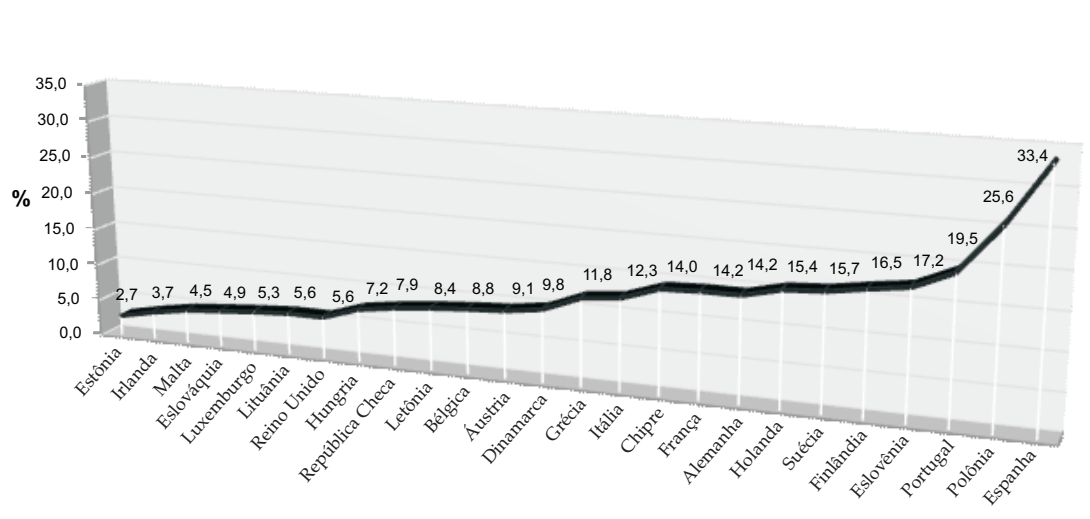

Fonte: Eurostat, LFS (http:/ /epp.eurostat.ec.europa.eu). 
partir do indicador da Organização para Cooperação e Desenvolvimento Econômico - $\mathrm{OCDE}^{11}$, com base na legislação de proteção do emprego - de que o país tem um mercado de trabalho muito rígido, questão que analisaremos detalhadamente mais adiante. Outro dado surpreendente é que a Dinamarca, como país modelo da chamada flexigurança, tem apenas 9,8\% de contratos temporários, uma das taxas mais baixas da UE, juntamente com a Irlanda e o Reino Unido, excetuando os países do leste.

Serão esses dados conjunturais ou se verifica de fato uma tendência generalizada e duradoura, segundo o trabalho temporário, no sentido da dualização dos mercados de trabalho, isto é, trata-se de uma tendência de aspecto mais estrutural? Para responder a essa pergunta, procedemos a uma análise diacrônica tendo em conta a evolução desse fenômeno nos últimos vinte $\operatorname{anos}^{12}$ (Gráfico 2).

Verifica-se que o trabalho temporário se tem generalizado nos últimos vinte anos nos países-membros da UE, não sendo, portanto, um fenômeno de natureza conjuntural, mas há exceções. Há países que, ao contrário da tendência geral, regrediram no uso de contratos a prazo, como Dinamarca, Grécia, Reino Unido, Irlanda e Espanha, embora es-

Gráfico 2

Evolução do Trabalho Temporário por País (1985-2005)

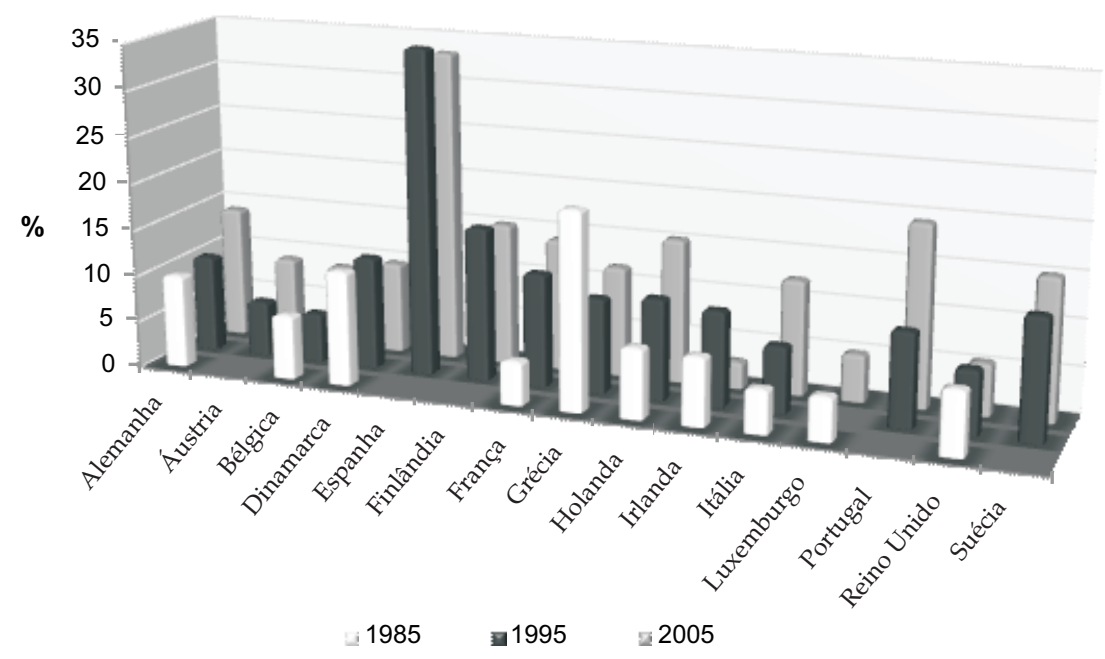

Fonte: Eurostat, LFS (http:/ / epp.eurostat.ec.europa.eu). 
se grupo apresente também situações diferenciadas entre si. Reino Unido e Dinamarca, por exemplo, mostram pequenas oscilações ao longo dos últimos vinte anos. A Espanha, inserindo-se no grupo dos países no qual a taxa de trabalho temporário decresceu, surge como um caso paradigmático na medida em que apresenta uma das taxas mais elevadas de todos os países da UE, como se referiu (Gráfico 2) ${ }^{13}$.

A tese da generalização da precariedade do emprego na UE não se verifica, portanto, embora afete a maioria dos países de forma diferenciada, sendo que, nesses casos, se afirma como um traço estrutural na reconfiguração dos mercados. Como explicar essas diferenças? As razões são certamente multifatoriais. As interpretações de natureza macroeconômica explicam, em grande medida, as necessidades de ajustamento do volume de emprego em períodos de crise e, por conseguinte, as condições propícias para um aumento do desemprego e da precariedade. No entanto, o comportamento das empresas deve também ser levado em conta, sobretudo em setores que mobilizam mão-de-obra pouco qualificada e em que as taxas de desemprego são elevadas. Nesses casos, em que Portugal se situa claramente, estão criadas condições propícias para um aumento do trabalho temporário.

Sejam quais forem as explicações, o fato é que, a partir dos dados aqui apresentados, se evidencia que a tendência de precarização do trabalho na Europa é de natureza estrutural em grande parte dos países, por oposição a outros em que esse fenômeno é relativamente reduzido e estabilizado no tempo. A questão que se impõe é então saber o que se passa nos países que fazem exceção a esse modelo de aumento sustentado da expansão do trabalho temporário. Uma hipótese bastante plausível é que os países com uma política mais liberal de demissões - como a Dinamarca e o Reino Unido - não precisam recorrer ao trabalho temporário como medida de ajustamento do volume de emprego em face das necessidades das empresas ${ }^{14}$. Isso explicaria o fato de os países nos quais as barreiras jurídicas às demissões são mais fortes serem os países onde o trabalho temporário tende a expandir-se mais. Isto é, nos países em que as demissões não estão liberalizadas, os empregadores usam uma espécie de mecanismo de liberalização controlada, chamemos assim, que é o recurso ao trabalho temporário. Esse é claramente o caso de Portugal no sentido em que, de acordo com o indicador da OCDE sobre proteção do emprego, o grau de dificuldade em demitir trabalhadores com contrato sem termo põe Portugal acima da média européia (Dornelas, 2006:186). 
Em termos genéricos, podemos concluir que os mercados de trabalho na Europa mostram uma mudança estrutural indicando a emergência de uma nova relação salarial, a que chamaremos de neoconcorrencial, na medida em que todos os países avançam para uma maior liberalização das relações de emprego, liberalização que tem expressões particulares em cada um dos países.

\section{O FENÔMENO ATINGE TODOS OS TRABALHADORES OU, PELO CONTRÁRIO, TEM UM IMPACTO GERACIONAL?}

Como se pode verificar no Gráfico 3, a geração dos mais jovens (15-24 anos) é a mais afetada pelo trabalho temporário ${ }^{15}$ em todos os países europeus, sem exceção.

Contudo, não podemos concluir sobre uma clivagem geracional ${ }^{16}$, na medida em que são jovens que podem estar ainda na escola ou em processo de inserção profissional. Temos então de admitir que esse indicador por si só não elucida nossa questão de fundo. A diferenciação entre países em face do problema que aqui nos ocupa parece fazer-se com maior acuidade nas faixas etárias mais elevadas. Com efeito, a taxa de penetração do trabalho temporário diminui, globalmente, na geração adulta (25-49 anos) e ainda mais na geração mais idosa. Nos adultos, é

\section{Gráfico 3}

Trabalho Temporário por Grupo Etário e País (2005)

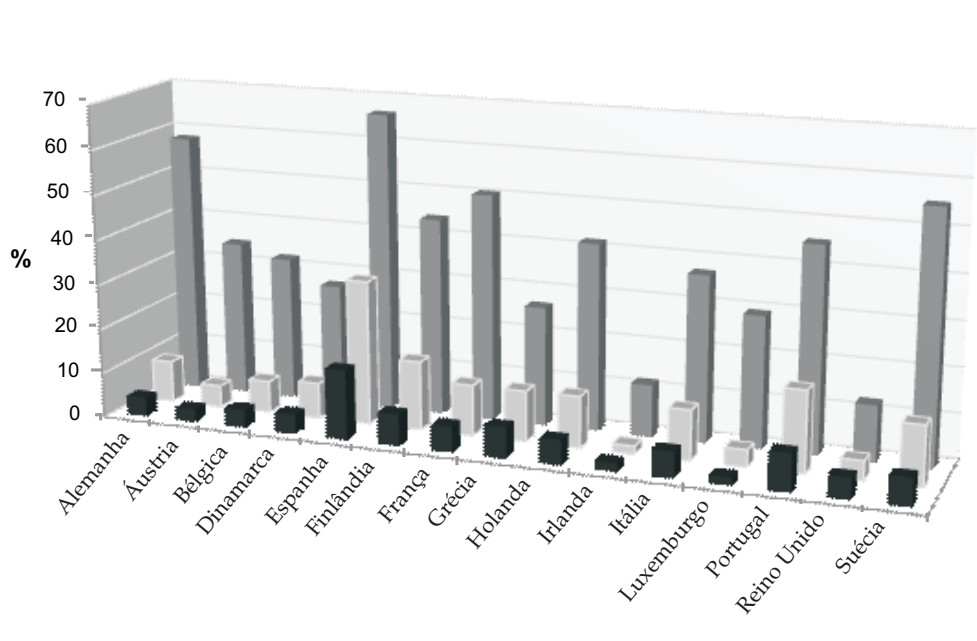

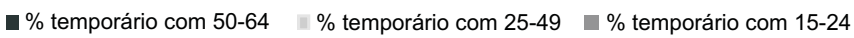

Fonte: Eurostat, LFS (http:/ / epp.eurostat.ec.europa.eu). 
menor em Luxemburgo, Irlanda, Áustria, Bélgica, Reino Unido e Dinamarca. No extremo oposto, estão Portugal, Espanha, Finlândia e Suécia, com as taxas mais elevadas de penetração do trabalho temporário na população adulta.

Para uma análise mais aprofundada, que permite esclarecer a hipótese do efeito geracional, optamos por analisar separadamente a evolução das condições de inserção no emprego de gerações distintas em fases diferentes do ciclo de vida profissional.

\section{A Evolução do Trabalho Temporário na Inserção Profissional dos Jovens de Três Gerações (1985-2005)}

Comparando as condições de inserção profissional de três gerações de jovens (15-24 anos) nos últimos vinte anos (Gráfico 4), concluímos que o padrão de precarização - aqui medido pela taxa de trabalho temporário - na inserção profissional se tem agravado, nas últimas décadas, de geração para geração, em grande parte dos países.

Constituem exceção a esse padrão de evolução Dinamarca, Irlanda, Reino Unido, Grécia, Finlândia e Espanha ${ }^{17}$. No entanto, sublinhe-se que, apesar da diminuição do trabalho temporário nesses países na úl-

\section{Gráfico 4}

Evolução do Trabalho Temporário nos Processos de Inserção Profissional dos Jovens (15-24 anos), em Três Gerações Distintas, por País (1985-2005)

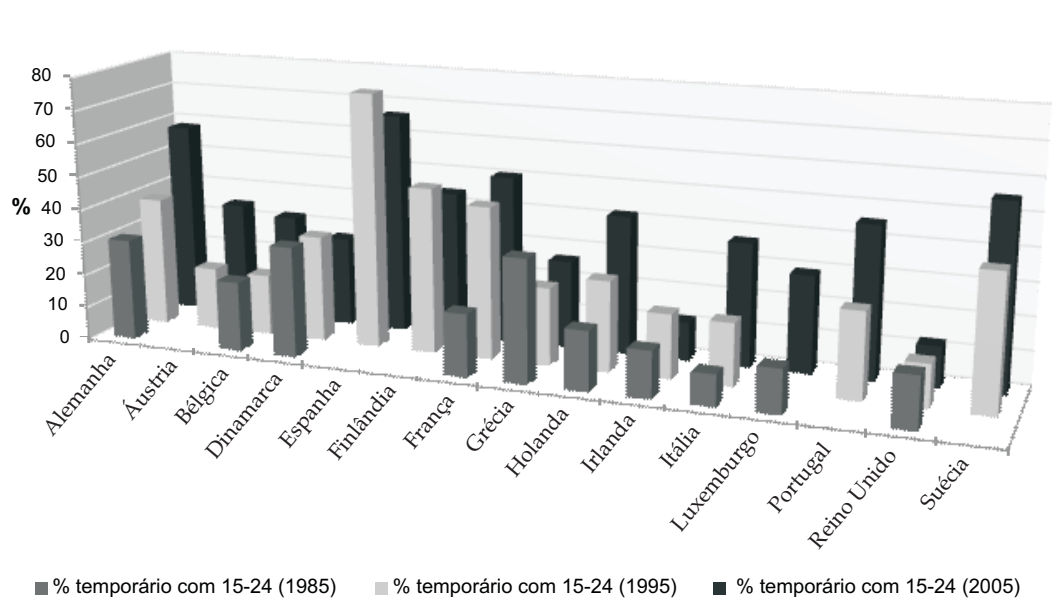

Fonte: Eurostat, LFS (http:/ / epp.eurostat.ec.europa.eu). 
tima década, o caso da Espanha é substancialmente diferente, dada a elevadíssima taxa de trabalho temporário que apresenta e que é, juntamente com a Alemanha, uma das mais elevadas da Europa na população jovem.

Tratando-se de jovens, é bem provável que essa situação de trabalho temporário se deva a características inerentes ao processo de inserção no mercado de trabalho, como referimos anteriormente, ou mesmo a opções pessoais decorrentes, por exemplo, da conciliação entre trabalho e escola. A análise das razões que os jovens declaram estar na base de sua situação de trabalhador temporário (Figura 1) surge assim como um indicador fundamental para uma melhor compreensão dessa situação $0^{18}$.

Na Dinamarca, na Alemanha e na Itália, a situação de precariedade dos jovens explica-se majoritariamente pelo fato de estarem ainda no siste-

Figura 1

Perfis-Tipo dos Países Segundo as Razões Referidas pelos Jovens (15-24 Anos) para Terem Trabalho Temporário (2005)

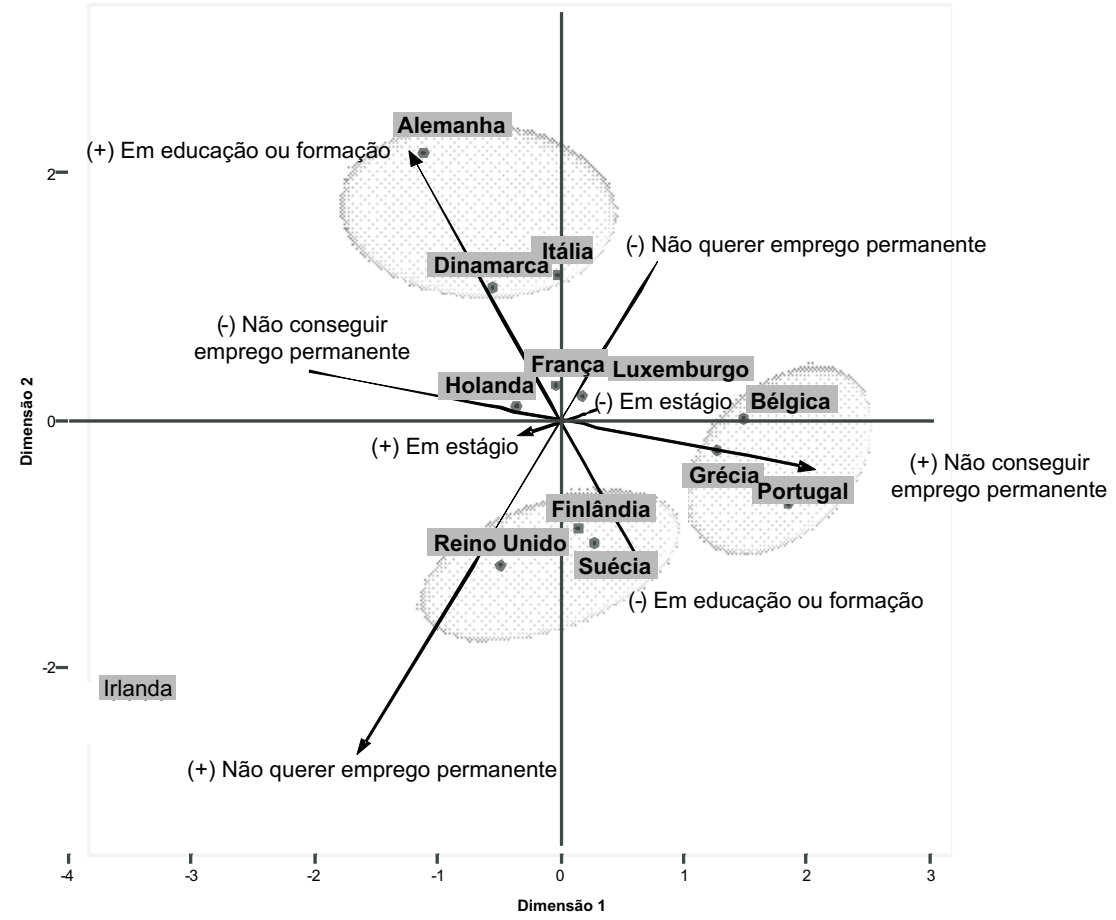

Fonte: Eurostat, LFS (http:/ / epp.eurostat.ec.europa.eu). 
ma de ensino/formação ${ }^{19}$, o que relativiza ainda mais as taxas de trabalho temporário na Dinamarca ${ }^{20}$.

Os jovens da Finlândia, da Suécia e do Reino Unido balançam entre não querer e não conseguir emprego permanente, sendo marcadamente a Irlanda o país em que os jovens alegam a voluntariedade do trabalho temporário. Podemos ainda observar um grupo de países - Bélgica, Grécia e Portugal - em que a razão mais referida é a de que não conseguem encontrar um emprego efetivo, indicando claras dificuldades de inserção profissional e uma importante diferença em comparação a países como Dinamarca, Alemanha e mesmo Itália, no que diz respeito à relação com o sistema de ensino/formação.

No que tange aos jovens franceses, podemos concluir que eles estão tripartidos entre: os que não querem emprego permanente, os que não conseguem emprego permanente e os que ainda estão estudando ou em formação.

\section{A Evolução do Trabalho Temporário na População Adulta (25-49 anos) em Três Gerações (1985-2005)}

A penetração dos contratos a prazo é globalmente muito mais baixa nessa faixa etária do que nos jovens em todos os países, como vimos anteriormente (Gráfico 3).

A interpretação desses dados sugere duas explicações possíveis, eventualmente concomitantes. Por um lado a idéia de que nessa idade a fase de transição da escola para o mercado de trabalho pode estar ultrapassada, e isso se traduz em um reforço dos laços da relação de emprego, por via das políticas de gestão de pessoal das empresas, independentemente do quadro jurídico. Por outro, podemos estar perante um efeito geracional, em que a população adulta ainda não foi atingida pelas lógicas de liberalização dos mercados de trabalho, ainda que esse efeito possa ser diferenciado entre países, constituindo os tais núcleos duros. Comparando as condições de inserção da população adulta em três gerações distintas (Gráfico 5), tal como fizemos para os jovens, verificamos que a situação de precarização do trabalho se agravou, de geração para geração, na maioria dos países.

Ainda se verificam diferenças entre países, quer porque alguns deles apresentam taxas muito baixas em termos relativos, como Luxemburgo e Áustria, quer porque a tendência é de decréscimo - por exemplo, a Irlanda -, quer porque as oscilações são pequenas, como Dinamarca e 


\section{Gráfico 5}

Evolução do Trabalho Temporário na População Adulta (25-49 Anos), em Três

Gerações, por País (1985-2005)

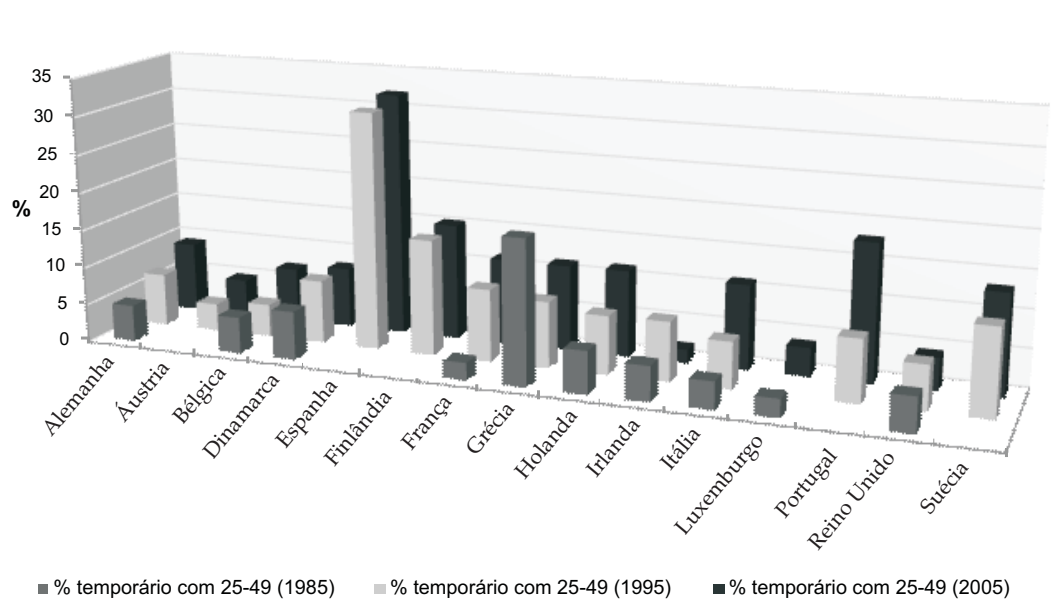

Fonte: Eurostat, LFS (http:/ /epp.eurostat.ec.europa.eu).

Reino Unido. A Grécia distingue-se desse grupo porque tem uma taxa relativamente mais elevada $(11,3 \%)$, apesar de apresentar um comportamento de oscilação entre gerações, mas com uma clara tendência de decréscimo ao longo desse período. Refira-se ainda o caso da Finlândia, cujas características de inserção no emprego se mantêm idênticas na última década $(15,3 \%)$.

Os dados indicam, portanto, que o trabalho temporário também se tem expandido de geração para geração nos adultos, embora de forma mais lenta do que nos jovens e com variações assinaláveis entre países. Portugal é o país que, depois da Espanha (32,1\%), apresenta a maior porcentagem $(18,0 \%)$ de trabalho temporário nessa geração, com uma diferença importante: enquanto a Espanha apresenta sinais de retrocesso, Portugal duplicou a porcentagem de trabalho temporário na última década, tendo-se agravado nitidamente as condições de inserção profissional da população adulta entre gerações.

Saber se o trabalho temporário é uma opção dos indivíduos ou um constrangimento e quais são as razões que justificam essa situação é essencial para uma interpretação rigorosa dos dados. Na Figura 2, podemos observar os perfis-tipo de comportamento dos diversos países ${ }^{21}$ em relação a essa questão. 
Figura 2

Perfis-Tipo dos Países Segundo as Razões Referidas pelos Adultos (25-49 Anos) para Terem Trabalho Temporário (2005)

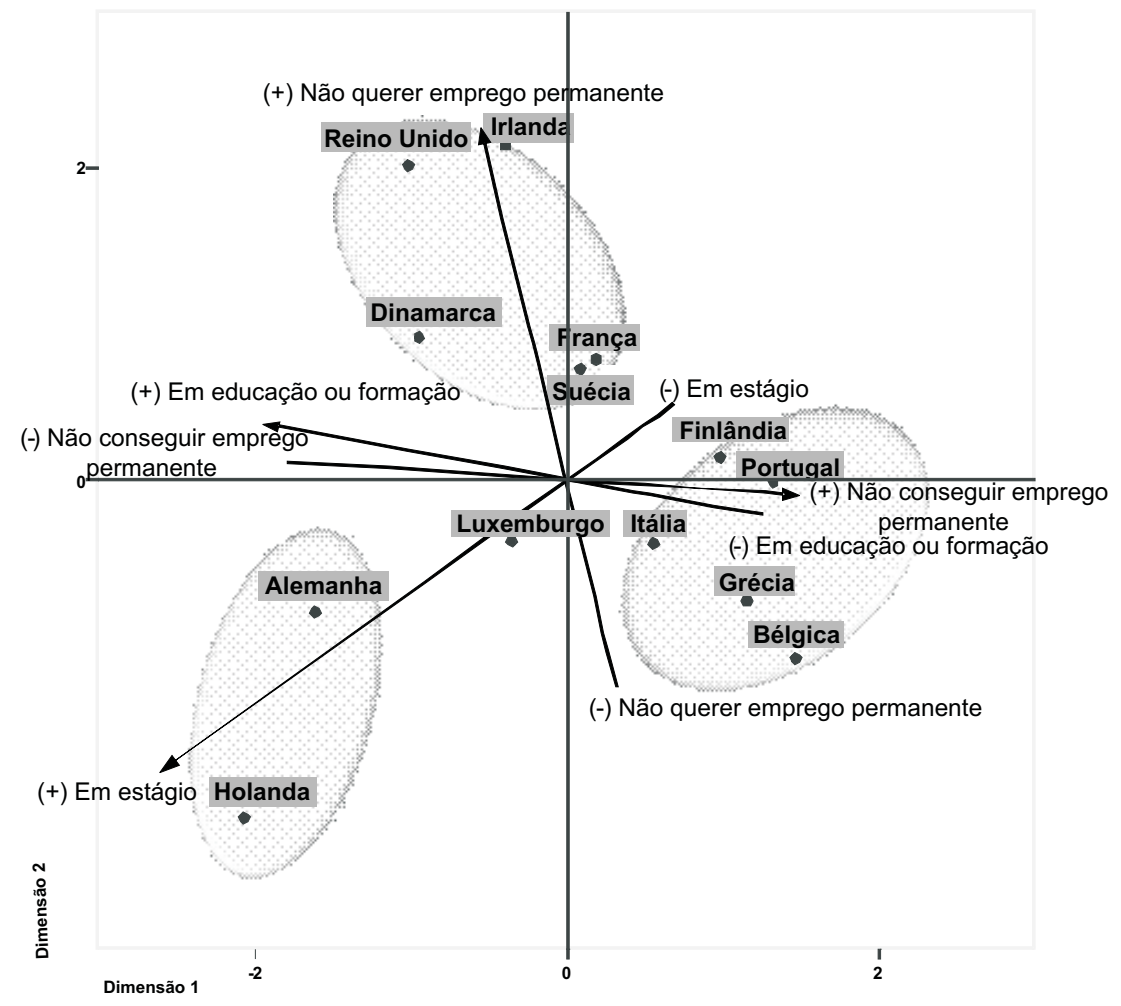

Fonte: Eurostat, LFS (http:/ /epp.eurostat.ec.europa.eu).

Reino Unido, Irlanda, França, Dinamarca e Suécia destacam-se por formarem um conjunto no qual a situação de trabalho temporário como opção é a mais elevada, não obstante a razão não conseguir emprego permanente ser a principal. Nos casos de Reino Unido e Dinamarca, essa opção está claramente associada a taxas mais elevadas de indivíduos que estão em educação ou em formação, corporizando a política do lifelong learning que a UE procura implementar. Permanecer em educação ou em formação é também uma razão com destaque na Alemanha, mas o traço distintivo desta em relação a outros países é a situação de trabalho temporário associado a estágios, razão também comum em Luxemburgo, que é o país líder nessa escolha.

Outro grupo de países, que inclui Finlândia, Portugal, Itália, Grécia e Bélgica, distingue-se pelo fato de o trabalho temporário ser claramente 
um constrangimento, na medida em que o que os indivíduos procuram é um emprego permanente. Nesse grupo de países, a educação/formação não se configura como uma opção dos indivíduos que estão na situação de trabalho temporário. Políticas sociais diferenciadas justificam, provavelmente, a diferenciação entre esses comportamentos-tipo.

Em termos mais gerais, podemos concluir que a análise desse indicador reforça a idéia de que a precarização tende a instalar-se na geração adulta, sendo que os fatores que mais diferenciam os países são, por um lado, a maior ou a menor extensão desse fenômeno e, por outro, o caráter de (in)voluntariedade com que as pessoas aceitam essa forma de emprego precário. Aceitar voluntariamente um trabalho temporário parece estar associado a projetos de educação/formação ou a outras formas de ocupação, como os estágios.

\section{A Evolução do Trabalho Temporário na População Sênior (50-64 anos) em Três Gerações (1985-2005)}

Vejamos agora o que se passa nas condições de inserção profissional dos mais idosos para aferirmos: em que medida podemos reforçar, ou não, a hipótese do que designamos como efeito geracional; e se há heterogeneidade entre países segundo certos comportamentos-tipo também nessa faixa etária.

Como vimos anteriormente (Gráfico 3), a penetração do trabalho temporário na população mais idosa é menor do que nos outros grupos. Com efeito, a porcentagem de trabalho temporário diminui em todos os países à medida que a idade aumenta, sendo mais baixa nos trabalhadores que têm entre 50 e 64 anos. Esse dado parece confirmar a idéia de um núcleo duro, com condições de inserção de tipo monopolista, mas tende a refutar a idéia de uma tendência de expansão generalizada de precarização do trabalho a todas as gerações nos países da UE. Mas será mesmo assim? Como vimos, a análise comparativa das condições de inserção nas gerações mais novas nas últimas duas décadas tende a relativizar essa hipótese. Vejamos o que se passa, usando a mesma metodologia, na geração dos seniores.

O Gráfico 6 permite-nos concluir que a tendência é de aumento do trabalho temporário, de geração para geração, também nesse grupo etário, em todos os países europeus, com exceção da Irlanda, do Reino Unido e da Grécia, confirmando a excepcionalidade desses países nas outras faixas etárias. Registre-se que a Dinamarca não se afasta muito 


\section{Gráfico 6}

Evolução do Trabalho Temporário nos Seniores (50-64 Anos), em Três Gerações, por País (1985-2005)

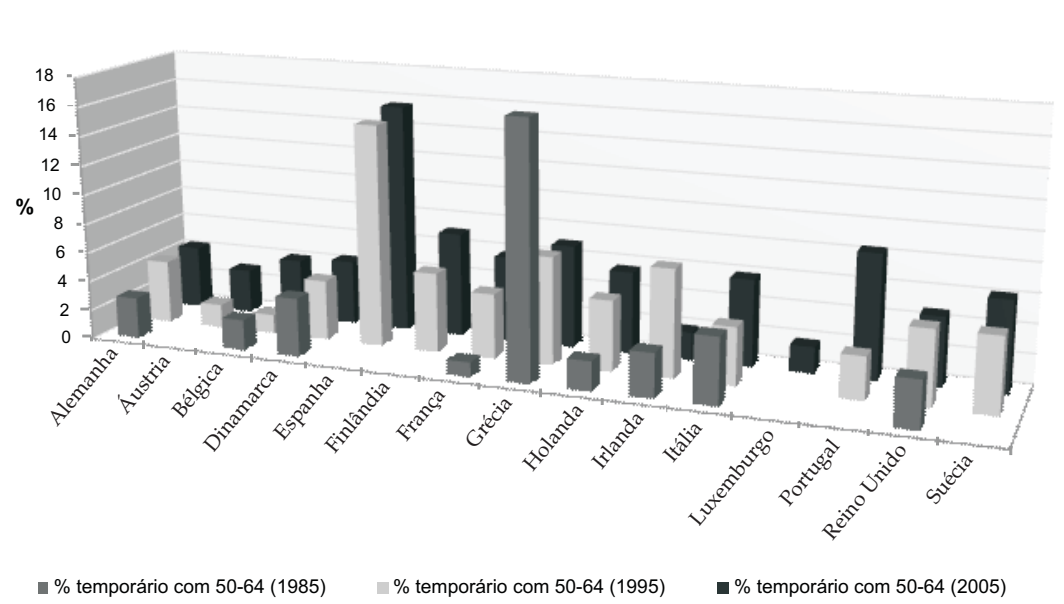

Fonte: Eurostat, LFS (http:/ / epp.eurostat.ec.europa.eu).

desse grupo, mantendo um traço distinto ao longo do tempo e entre gerações, que se verifica também nessa faixa etária.

Portugal registra maior tendência para a precarização nesse grupo não apenas por apresentar a segunda taxa mais elevada, mas também porque foi o país em que esse fenômeno mais se expandiu na última década. Aparece, portanto, ao lado da Espanha, como o país com maior penetração de trabalho temporário também na geração dos mais velhos.

Contudo, esses dados devem ser analisados com precaução, tal como relatamos sobre os jovens, atendendo ao fato de que, nessa faixa etária e no período considerado, muitas pessoas podem ter abandonado o mercado de trabalho para a inatividade - como Madsen (2002) refere para o caso dinamarquês -, aliviando as pressões sobre o emprego por meio de mecanismos de reforma antecipada por mútuo acordo, por exemplo. As razões referidas pelos indivíduos para no final da vida ativa se encontrarem em uma situação de trabalho temporário pode, no entanto, ajudar a elucidar essa questão.

Na generalidade dos países, com exceção do Reino Unido, a principal razão relaciona-se ao fato de as pessoas não conseguirem encontrar emprego permanente, confirmando a idéia de que existem dificulda- 
des de reinserção no mercado de trabalho e que afetam os mais velhos de forma muito particular. Cabe sublinhar que Bélgica, Grécia e Portugal são os países que apresentam um quadro de maiores dificuldades, registrando taxas entre $90 \%$ e $94 \%$ de indivíduos que não conseguem encontrar emprego permanente nessa faixa etária.

Na Figura 3, podem ser visualizados países com perfis-tipo de comportamento idêntico, não obstante a quase genérica supremacia da razão não conseguir emprego permanente ${ }^{22}$.

Identificam-se assim três grupos de países com perfis distintos. Um dos perfis associa os países com maior porcentagem de trabalho temporário com o não conseguir emprego permanente. São os casos de Dinamarca, Finlândia, França, Alemanha, Itália e Suécia.

O Reino Unido aparece isolado porque, ao contrário daqueles países, a razão preponderante para o trabalho temporário é que este é uma opção dos indivíduos.

Figura 3

Perfis-Tipo dos Países Segundo as Razões Referidas pelos Indivíduos Seniores (50-64 Anos) para Terem Trabalho Temporário (2005)

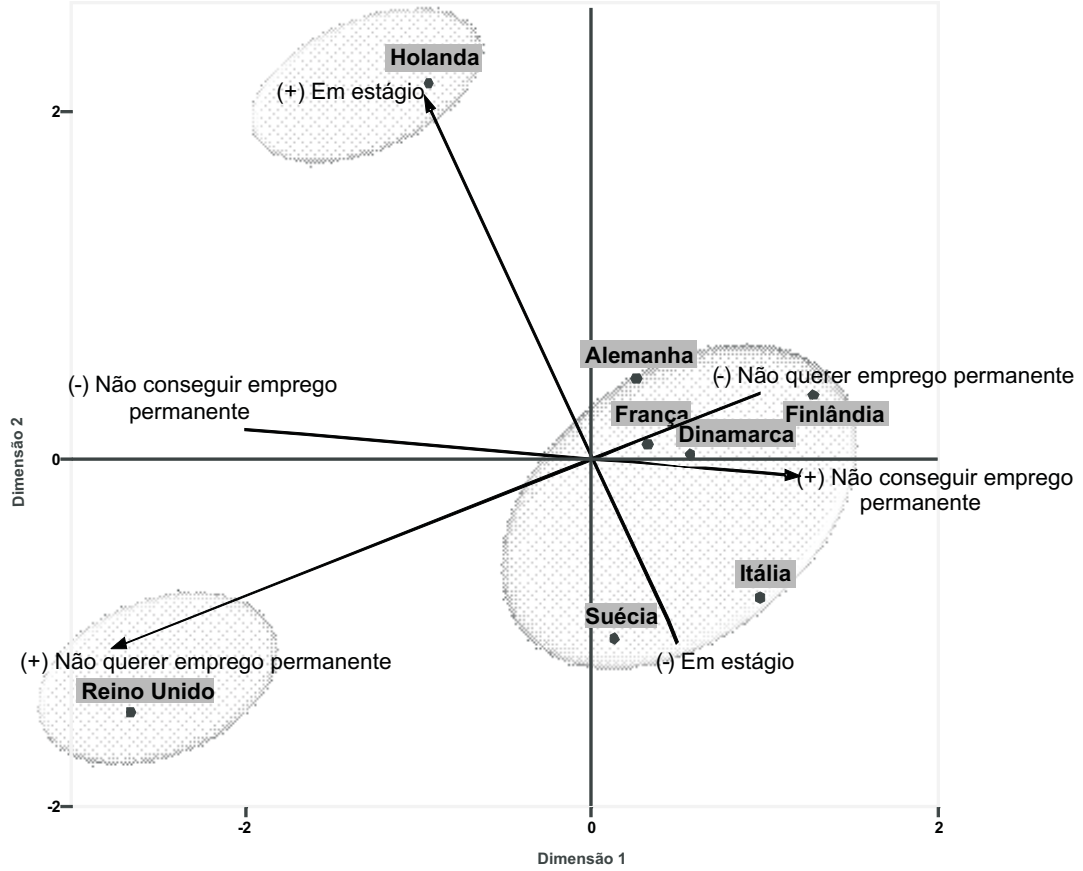

Fonte: Eurostat, LFS (http:/ / epp.eurostat.ec.europa.eu). 
A Holanda, tal como o Reino Unido, apresenta, por um lado, a menor taxa de trabalho temporário e, por outro, a mais elevada taxa de indivíduos em que essa situação se justifica em virtude da realização de estágios.

\section{CONCLUSÃO}

A análise de precarização do emprego na Europa - aqui medida por meio da taxa de trabalho temporário - revela que esse é um fenômeno comum a todos os países, embora seu peso relativo na população empregada seja diferenciado. Assim, a Espanha apresenta a taxa mais elevada de trabalho temporário, seguida da Polônia e de Portugal. Países como Dinamarca, Irlanda e Reino Unido apresentam, ao contrário, as taxas mais baixas, se excetuarmos os países do leste.

Os dados mostram ainda que a tendência de precarização do emprego na Europa é de natureza estrutural em grande parte dos países, por oposição a outros em que esse fenômeno é relativamente reduzido e estabilizado nos últimos vinte anos. Com efeito, há países que, ao contrário da tendência geral, regrediram no uso de contratos a prazo, como Dinamarca, Grécia, Reino Unido, Irlanda e Espanha. Esse grupo apresenta também situações diferenciadas entre si: o Reino Unido e a Dinamarca têm taxas relativamente baixas, apresentando pequenas oscilações nesse período de tempo, enquanto a Espanha, por exemplo, apresenta um decréscimo de trabalho temporário na última década, mas continua com uma das taxas mais elevadas da UE.

A tese da generalização do trabalho precário na UE, portanto, não se verifica, embora afete a maioria dos países de forma diferenciada, sendo que, nesses casos, se afirma como um traço estrutural na reconfiguração dos mercados de trabalho.

A questão que se impõe é então saber o que se passa nos países que fazem exceção a esse modelo de aumento sustentado da expansão do trabalho temporário. Uma hipótese bastante plausível é que os países com uma política mais liberal das demissões - sendo paradigmáticos a Dinamarca e o Reino Unido - não precisam recorrer ao trabalho temporário como medida de ajustamento do volume de emprego em face das necessidades das empresas. Isso explicaria por que os países onde as barreiras jurídicas às demissões são mais fortes são aqueles em que o trabalho temporário tende a expandir-se mais. Nesses casos, os empregadores tendem a recorrer a formas precárias de contratação como um mecanismo de liberalização controlada, digamos assim. Esse é clara- 
mente o caso de Portugal. Segundo a OCDE, é um dos países mais protetores dos empregos permanentes e contra as demissões individuais por via jurídica, o que não impede, como vimos nesta análise, que a liberalização do mercado se faça pela expansão do trabalho temporário - e, eventualmente, por outras formas atípicas de emprego. Também é um dos países que mais aumentou a taxa de trabalho temporário nos últimos vinte anos em todos os grupos etários.

Em termos mais gerais, podemos concluir que os mercados de trabalho na Europa mostram uma mudança estrutural no sentido de uma redefinição das relações de emprego, indicando a emergência de uma nova relação salarial, que designamos como neoconcorrencial, na medida em que todos os países avançam para uma maior liberalização das relações de emprego, seja pela liberalização das demissões individuais e/ou coletivas, seja pela expansão do trabalho temporário ou pela combinação de ambas ${ }^{23}$.

Para uma análise mais aprofundada, que permitisse esclarecer a hipótese do efeito geracional, optamos por analisar separadamente a evolução das condições de inserção no emprego de gerações distintas, em fases diferentes do ciclo de vida profissional, ao longo dos últimos vinte anos. Concluiu-se que a geração dos mais jovens é a mais afetada pelo trabalho temporário em todos os países europeus, sem exceção. Não podemos, no entanto, extrair daí que exista uma clivagem geracional, de dualização do mercado pela precarização, que atinge sobretudo os mais jovens. Com efeito, na faixa etária dos 15 aos 24 anos, é plausível admitir que muitos desses jovens podem estar ainda na escola ou em processos de inserção profissional que, como se sabe, tendem a prolongar-se no tempo. Foi o que se concluiu pela análise das razões que levam as pessoas a terem um trabalho temporário. Em um quadro diferente, o mesmo tipo de raciocínio se aplica ao grupo etário dos 50 aos 65 anos, seja porque estão em fase de transição para a saída do mercado, beneficiando-se de mecanismos de reforma antecipada, seja por outros motivos de natureza semelhante muito utilizados pelas empresas nos anos 1980 e 1990. Por essas razões, a diferenciação entre países parece fazer-se com mais acuidade na geração dos 25 aos 49 anos.

Cabe destacar, no entanto, que a principal razão pela qual a maioria das pessoas tem um trabalho temporário é o fato de não conseguir encontrar um emprego permanente, sobretudo a partir dos 25 anos. A situação é majoritariamente vivida como um constrangimento, e não 
como uma opção, em quase todos os países - embora com algumas diferenças - e se agrava na geração dos mais velhos.

No grupo dos 25 aos 49 anos, concluiu-se que o trabalho temporário se tem alastrado de geração para geração - tal como nos outros grupos etários -, embora de forma mais lenta do que nos jovens e com variações assinaláveis entre países. Portugal é o país que, depois da Espanha $(32,1 \%)$, apresenta a maior porcentagem $(18,0 \%)$ de trabalho temporário nessa geração, com uma diferença importante: enquanto a Espanha apresenta sinais de retrocesso, Portugal duplicou a porcentagem de trabalho temporário na última década, tendo-se agravado bastante as condições de inserção profissional da população adulta, entre gerações.

Em termos mais gerais, podemos concluir que a análise desse indicador reforça a idéia de que o emprego precário se tem instalado progressiva e persistentemente em todas as gerações, sendo que os fatores que mais diferenciam os países são, por um lado, a maior ou menor extensão desse fenômeno e, por outro, o caráter de (in)voluntariedade com que as pessoas aceitam um trabalho temporário. Ter um trabalho temporário como opção parece estar associado a projetos de educação / formação em uma lógica de lifelong learning ou de outras formas de ocupação - como os estágios -, sendo esse o principal fator de diferenciação entre países. 


\section{NOTAS}

1. A definição de precariedade do emprego é objeto de controvérsias no campo da sociologia e tem mesmo significados diferentes segundo os países. Os franceses e os alemães, por exemplo, nos anos 1990, quando falavam em precariedade, referiam-se à instabilidade do emprego decorrente do uso crescente de contratos de emprego a termo certo, enquanto os ingleses, para as mesmas condições de emprego, preocupavam-se sobretudo com os baixos salários e as más condições de trabalho que lhes eram inerentes. Enquanto uns sublinhavam a expansão do emprego precário, os outros falavam sobretudo em bad jobs (Paugam, 2000:18). Os termos do debate foram evoluindo, mas estamos ainda longe de uma estabilização do conceito. Ver Paugam (2000); Le Blanc (2007); Cingolani (2005); Auer e Gazier (2006).

2. Emprego de contrato de duração determinada ou contrato a prazo, que incluem empregos de substituição, intermitentes ou em regime de subcontratação sem contrato efetivo (Kováks, 2002; Vaz, 1997).

3. Pressuposto sustentado em um estudo recente, com base no International Social Survey Programme - ISSP, de 2006, em um conjunto de países europeus (Freire, 2008). Esse estudo revela que, em todos os países analisados, o fator que os indivíduos mais valorizam é a segurança de emprego, valorização que é, em termos médios, superior ao valor atribuído ao salário.

4. A relação salarial é definida como o conjunto das condições jurídicas e institucionais que regem a utilização e a reprodução do trabalho assalariado. Do ponto de vista mais operativo, a relação salarial refere-se às seguintes componentes: organização do trabalho; padrões de qualificação e de mobilidade dos trabalhadores; modelos de formação dos salários (direto e indireto); e modelos de consumo. A variável-chave na caracterização da relação salarial é o tipo de contrato de trabalho (ou sua ausência), na medida em que revela o grau de integração dos trabalhadores no mundo do trabalho e do consumo.

5. Em 2005, a Dinamarca (4,9\%), juntamente com Irlanda, Luxemburgo, Holanda e Reino Unido, apresentou uma das taxas mais baixas de desemprego (abaixo dos $5 \%$ ) nos países considerados.

6. Limitando a possibilidade de reforma antecipada - muito incentivada em alguns países nos anos 1980 e 1990 - e aumentando a idade da reforma.

7. Mais especificamente, o Detailed Annual Survey Results e o Detailed Quarterly Survey Results.

8. Involuntário no sentido em que as pessoas aceitam um emprego em tempo parcial, porque não conseguem encontrar um emprego em tempo integral.

9. Segundo um estudo com base no ISSP, de 2006, que inclui dez países europeus Grã-Bretanha, Hungria, Irlanda, Suécia, Eslovênia, Espanha, França, Portugal, Dinamarca e Alemanha -, conclui-se pela existência de fortes indícios de trabalho clandestino em todos os países analisados (Oliveira, 2008).

10. Decorrendo de uma estratégia de contorno da legislação laboral, os chamados falsos trabalhadores independentes são, para todos os efeitos, equiparados a trabalhadores por conta de outrem, com exceção da relação jurídica de emprego, em que o trabalhador tem um contrato de trabalhador independente, como se se tratasse de uma profissão liberal. Estima-se que em Portugal existam atualmente 1.800.000 falsos trabalhado- 
res independentes, tendo o governo já anunciado medidas de combate a esse fenômeno de emprego precário.

11. Esse indicador é construído com base nas regras jurídicas que dificultam as demissões individual e coletiva e as limitações à contratação temporária (OCDE, 2004).

12. Nessa análise, eliminamos os países para os quais não existe informação disponível no período analisado e que são basicamente os países do leste da Europa. Por questões de coerência, análises mais detalhadas que apresentamos ao longo do texto também não incluem esses países.

13. Não havendo dados disponíveis para 1985, no caso da Espanha, apenas podemos avaliar a evolução na última década.

14. De acordo com a OCDE (2004), são esses os países que apresentam menor proteção do emprego do ponto de vista jurídico.

15. Esse indicador nos informa sobre a porcentagem de trabalhadores com trabalho temporário no grupo dos empregados em cada uma das três faixas etárias.

16. A noção de geração é objeto de atribuição de vários significados e, nesse sentido, pouco rigorosa. Alguns autores preferem usar a noção de cohorte, particularmente adequada para estudos longitudinais. Para uma discussão sobre essa problemática, ver Chauvel (1998). Neste artigo, usamos a noção de geração entendida como um conjunto de indivíduos que, em uma determinada época de sua vida, viveram uma determinada situação. Nesse caso, as condições de inserção no mercado de trabalho e, em particular, a relação de emprego. Usamos essa noção em duas acepções, uma sincrônica e outra diacrônica. A sincrônica diz respeito a diferentes grupos de idade na atualidade: os jovens (15-24 anos), os adultos (25-49 anos) e os seniores (50-64 anos); a segunda contempla grupos que se inseriam na mesma faixa etária em diferentes momentos (1985, 1995 e 2005).

17. Para a Espanha, só existem dados relativos aos últimos dez anos.

18. Importa referir que foram retiradas dessa análise a Áustria e a Espanha. O primeiro caso porque registra valores (e de 100\%) apenas em uma das razões (educação/formação); o segundo, por não haver informação disponível.

19. Observe-se que os vetores representados na Figura 1 referem-se a cada uma das quatro razões e as setas vão em direção às taxas mais elevadas.

20. Sublinhe-se que Dinamarca, Irlanda e Holanda apresentam também as taxas de desemprego jovem mais baixas dos países europeus em análise, com $8,6 \%$ para os dois primeiros países e $8,2 \%$ para o último no período considerado. Os países restantes apresentam uma taxa de desemprego acima dos dois dígitos.

21. Espanha e Áustria não figuram nesse mapa de perfis pelas razões referidas para a faixa dos 15 aos 24 anos.

22. Pela concentração de valores em uma única razão - Bélgica, Grécia, Portugal e Áustria - e pela ausência de valores em outros países - Espanha, Luxemburgo e Irlanda-, foram incluídos somente oito dos quinze países em análise.

23. A identificação mais rigorosa dos contornos dessa nova relação salarial abre pistas de investigação com recurso a outros indicadores, nomeadamente a qualificação dos trabalhadores, a organização do trabalho, a formação dos salários (direto e indireto) e os modelos de consumo dos trabalhadores. 


\section{REFERÊNCIAS BIBLIOGRÁFICAS}

AGHION, Philippe e COHEN, Élie. (2004), Éducation et Croissance. Paris, La Documentation Française.

AUER, Peter e GAZIER, Bernard. (2006), L'Introuvable Sécuritéde l'Emploi. Paris, Flammarion.

BECK, Ulrich. (1992), Risk Society. Towards a New Modernity. London, Sage.

BOYER, Robert. (1981), “Les Transformations du Rapport Salarial dans la Crise: Une Interprétation de ses Aspects Sociaux et Économiques". Critiques de l'Économie Politique, $\mathrm{n}^{\text {os }} 15 / 16$, pp. 185-228.

(1986), La Flexibilité du Travail en Europe. Paris, La Découverte.

CASTEL, Robert. (1995), Les Métamorphoses de la Question Sociale. Une Chronique du Salariat. Paris, Fayard.

. (2003), L'Insécurité Sociale, qu'est ce qu'être Protégé? Paris, Seuil/La République des Idées.

CHAUVEL, Louis. (1998), Le Destin des Générations, Structure Sociale et Cohortes en France au XXe Siècle. Paris, PUF.

CINGOLANI, Patrick. (2005), La Précarité. Paris, PUF.

DORNELAS, António (coord.). (2006), Livro Verde sobre as Relações Laborais. Lisboa, Ministério do Trabalho e da Solidariedade Social.

DUBET, François. (2006), Injustices, l'Expérience des Inégalités au Travail. Paris, Seuil.

ESPING-ANDERSEN, Gosta. (1990), The Three Worlds of Welfare Capitalism. Cambridge, Polity Press.

FERRERA, Maurizio, HEMERIJCK, Anton e RHODES, Martin. (2000), O Futuro da Europa Social. Repensar o Trabalho e a Protecção Social na Nova Economia. Oeiras, Celta.

FREIRE, João (coord.). (2008), Orientações perante o Trabalho \& Relações Laborais, Relatório final. Lisboa, ICS/Ministério do Trabalho e da Solidariedade Social.

GEER, John Van. (1993a), Multivariate Analysis of Categorical Data: Theory. London, Sage, vol. 2.

(1993b). Multivariate Analysis of Categorical Data: Applications. London, Sage, vol. 3.

GIFI, Albert. (1996), Nonlinear Multivariate Analysis. London, John Wiley \& Sons.

KOVÁCS, Ilona. (2002), As Metamorfoses do Emprego. Oeiras, Celta.

(org.). (2005), Flexibilidade de Emprego, Riscos e Oportunidades. Oeiras, Celta.

LE BLANC, Guillaume. (2007), Vies Ordinaires. Vies Précaires. Paris, Seuil.

MADSEN, Per Kongshøj. (2002), The Danish Model of "Flexicurity" - A Paradise with some Snakes. Trabalho apresentado na European Foundation for the Improvement of Living and Working Conditions. Brussels.

(2004), “The Danish Model of 'Flexicurity': Experiences and Lessons". Transfer, vol. $10, \mathrm{n}$ - 2, pp. 187-207. 
MEULMAN, Jacqueline, KOOIJ, Anita e HEISER, Willem. (2004), “Principal Components Analysis with Nonlinear Optimal Scaling Transformations for Ordinal and Nominal Data", in D. Kaplan (ed.), The Sage Handbook of Quantitative Methodology for the Social Sciences. Thousand Oaks, Sage, pp. 49-70.

OCDE - Organização para Cooperação e Desenvolvimento Econômico. (2004), Perspectives de L'Emploi de l'OCDE. Paris, OCDE.

- (2005), Ageing and Employment. Paris, OCDE.

_. (2006), Live Longer. Work Longer. Paris, OCDE.

OLIVEIRA, Luísa. (2008), “Desemprego e Inactividade”, in J. Freire (coord.), Orientações perante o Trabalho \& Relações Laborais. Relatório final. Lisboa, ICS/Ministério do Trabalho e da Solidariedade Social, pp. 189-225.

PAUGAM, Serge. (2000), Le Salarié de la Précarité. Paris, PUF.

RODRIGUES, Maria João. (1988), O Sistema de Emprego em Portugal. Crise e Mutações. Lisboa, Dom Quixote.

_ (coord.). (2000), Para uma Europa da Inovação e do Conhecimento. Oeiras, Celta.

SENNETT, Richard. (2001), A Corrosão do Carácter. As Consequências Pessoais do Trabalho no Novo Capitalismo. Lisboa, Terramar.

VAZ, Isabel Faria. (1997), As Formas Atípicas de Emprego e a Flexibilidade do Mercado de Trabalho. Lisboa, Ministério da Qualificação e Emprego. (Colecção Estudos). 


\section{ABSTRACT}

Precarious Employment in Europe

This article examines the hypothesis of the emergence of a post-Fordist wage relationship, exploring one of this concept's components: the transformation of permanent employment into precarious employment. Based on Eurostat data, the article analyzes the evolution of the temporary work indicator in the last twenty years and the reasons that lead workers to accept this situation, according to a generational matrix. The article concludes that there has been a structural change to the extent that all countries have moved towards greater flexibilization of employment relations through liberalization of layoffs, expansion of temporary work, or a combination of the two.

Key words: casualization; flexibilization of employment relations; Principal Components Analysis for Categorical Data - CatPca

\section{RÉSUMÉ}

\section{La Fragilité de l'Emploi en Europe}

Dans cet article, on cherche à poser l'hypothèse du surgissement d'un rapport salarial postfordiste, en examinant l'un des composants de ce concept: la transformation de l'emploi permanent en emploi précaire. À partir des données de l'Eurostat, on examine l'évolution du chiffre du travail temporaire dans les 20 dernières années et les raisons qui mènent les gens à accepter cette situation d'après une matrice générationnelle. Les conclusions vont dans le sens d'un changement structurel, dans la mesure où tous les pays s'orientent vers une plus grande déréglementation des rapports dans l'emploi, soit par la déréglementation des licenciements, soit par l'expansion du travail temporaire, ou par la combinaison des deux.

Mots-clé: fragilité; déréglementation des rapports dans l'emploi; Principal Components Analysis for Categorical Data - CatPca 